\title{
Comparison of Users' Attitude to Probability Notices on Random Type Item Providing Systems
}

\author{
Ayako Hiramatsu *
}

\begin{abstract}
This research is focused on users' behavior for the random type item providing system called "Gacha" in the social game of the smartphone application. Gacha includes gambling elements and has caused many problems like too much charge, not available rare items and so on. In order to follow the related laws and protect users, game providers have announced the provision rate of items by Gacha in accordance with the guidelines. This paper discusses whether the notice of probability influence to the users' attitude and what intention users have for Gacha. Questionnaires about playing social games and Gacha were provided 3 times to students. From the first questionnaire's result, it was clear that attitude for Gacha probability notice were different by charge experiences. Therefore other questionnaires results were analyzed dividing into charging and non-charging users and they were compared using structural equation modeling.
\end{abstract}

Keywords: gacha, questionnaire analysis, random type item providing, user behavior.

\section{Introduction}

The spread of smartphones is remarkable and is generally used as a mobile terminal to use Internet. In Japan, while the household penetration rate for smartphones was 9.7\% for 2010 years, it was $75.1 \%$ in 2017, and exceeded PCs and landlines [1]. In addition, according to private research, it was estimated that in 2019 it exceeded $85 \%$. Nearly half of downloads for smartphone apps seem to be game apps, and many users are enjoying games on their smartphones. A smartphone application game is often a social game in a broad sense in that it can be connected to other users on the premise of connection to the Internet.

Many of the social game applications have introduced a mechanism to make the transition to pay, offering a service that adds value to the free offering called freemiun [2]. In other words, it can be used almost free of charge, but if you need additional services such as obtaining advantageous items or extending the number of plays, you will be charged for a fee. There are two ways to obtain items by paying fees: purchase of the item as it is and item which can be obtained by electronic lottery (generally called "gacha"), so as to increase user's curiosity. The charge for obtaining the item is a charge for the most direct purpose of enjoying the game and the unit price is small. Therefore, there is a problem that the entire charge amount cannot be grasped, or becomes expensive while not aware [3]. A large charge has become a social problem. The Complete Gacha, where multiple items are available and rare items can be obtained, has been banned,

\footnotetext{
* Osaka Sangyo University, Osaka, Japan
} 
and since July 2012 the Consumers Affaires Agency has decided to apply for administrative sanctions under the Premiums and Representations Act.[4] The large charge problem, however, still continues [5]. Users complain that "the rare item is not set despite the large charge" and "the emission rate is set to a low level unreasonably." In order to follow the related laws and protect to users about these complaints, the Japan Online Games Association [6] and the Computer Entertainment Supplier's Association [7] set guidelines for the operation of the randomly providing item system in 2016, and members of the association should operate in accordance with these guidelines. If they follow these guidelines, users are shown the item emission rate for the gacha. In addition, the download service for apps is also required to disclose the appearance rate of gacha to users. Other studies have focused on the gambling factor of gacha and warned that social games can be a gateway to gambling [8]. However, gacha, which is often provided in Japan recently, is a means of purchasing items, not the purpose of gacha itself, and items are not cashable, so they are different from general gambling.

This research is focused on users' behavior for the random type item providing system (Gacha) in the social game of the smartphone application. There are many research about smartphone game users behavior [9][10][11][12]. The most interest matter is why users charge in games or what motivation users have for purchase items. Their main targets are not purchasing with Gacha system. A study about Gacha users [5] qualitatively analyzed perception of users and developers with interview. Guidelines are introduced, however, the influence of them is not analyzed. This paper is researched the probability notice influence to the users' behavior and what intention users have for Gacha [13][14], and compare users' attitude by charge or non-charge. It should be noted that, in the research on the behavior survey of the game user, the behavior is often different depending on the type of the game, so that a specific content is often assumed. This research aims to clarify the influence of gacha probability notation, and does not assume a specific game as a premise of the research from the viewpoint of gacha as an item acquisition method. Moreover, the above-mentioned research results have revealed that the behavior of the game user is easily influenced by personal circumstances such as economic reasons. Therefore, in this research, to make the attributes of the survey as uniform as possible and eliminate the influence of individual circumstances, the survey target was limited to university students.

\section{Item Sale with Gacha}

The randomly providing item system is generally called Gacha. Gacha is originally a capsule toy vending machine, and one capsule toy can be obtained by putting money and turning the handle. There is a lot of fun of lottery that the contents of the capsule toy can be understood only after obtaining it. Even for Gacha in social game applications, users charge in the games and turn Gacha as electronic lotteries to obtain items.

It is only after obtaining what kind of item it is. Although, in the case of the capsule toy gacha, what is present can be seen and it can be seen that the target will come out someday, the electronic lottery Gacha cannot see the entire contents. User cannot confirm what items are actually included and how many items are included in the Gacha, and cannot but trust the game operating company. There are many cases in which items desired to be obtained are not discharged in response to a large charge, and there are voices that are dissatisfaction and question the method of game management. In response to users complaining about how to operate the game, such as setting an unreasonable emission rate, however, there is no illegality in the operation itself and users' request was rejected even in the case of a large charge lawsuit[4]. 
Since many users are dissatisfied with Gacha, each association has formulated guidelines for Gacha in order to gain the trust of the users. The announcement and operation guidelines to sale items using random type item provision method formulated by Japan Online Game Association stipulates that information will basically be disclosed to users as matters concerning announcement, setting and operation of paid Gacha. In particular, it has become essential to announce the emission probability or the estimated price until acquisition for rare items. According to the guidelines established by the Computer Entertainment Supplier's Association, it is also decided to display an estimated price, odds, or an item provision ratio for rare items.

\section{Questionnaire for User Behavior}

\subsection{Outline of questionnaire}

Questionnaires have been executed three times to research the effectiveness of the social game guidelines that make game providers to disclose information to users. In the initial questionnaire in 2016, the subjects were 128 (108 men, 20 women), mainly college students in their early 20s. The second questionnaire was conducted in 2018, and the subjects were 227 university students (200 men and 27 women). The third questionnaire was conducted in 2019 , and the subjects were 202 university students (181 men, 21 women). The questions consist of the subject's attributes, the social game experience, the charge tendency, the motive to pull the Gacha, and the awareness about the probability notation. For improvement of question item based on result of last questionnaire, questions are a little different among each time. When questionnaires were conducted, about 10 students were interviewed each time and asked to answer in order to hear their direct opinions and feelings.

The first questionnaire executed in 2016 was preliminary. From this results, it was supposed that attitude for Gacha probability notice were different by charge experiences. Therefore, this research decided to analyze users dividing into charging and non-charging. In addition, the 2016 results show that a number of complex hypoth-eses about the relevance of reasons can be envisioned. In order to verify various complex association hypotheses, questionnaire design was conducted on the premise of analysis by structural equation modeling.

\subsection{Experience of social games and charges}

Users were asked about the usage time as a question about the experience of the social game. The following results mainly describe the results of the 2018 questionnaire, but the results for 2019 show almost the same tendency. About $70 \%$ play social games daily, but $10 \%$ of them do not use at all. The answer was divided into some pattern, but 2 hours or more were the most. However, about $35 \%$ of the subjects answered daily and 2 hours or more, it can be said that users who use 2 hours or more use almost every day.

In the question about trends of charge, a question asked if they had experience that purchase digital contents such as stickers, electronic books, music, etc. on smartphones as well as games, and about $77 \%$ had the purchase experience. The unit price of the products to be purchased was wide, ranging from 10 yen to 10,000 yen, and was relatively low at 1,000 yen or less. In addition, about half used prepaid cards as a payment method at that time. The question about charge in game apps is about $65 \%$ of those who have experienced 
charging, a slight decrease compared to digital content in general. Also, when questionnaire asked why users do not charge with multiple answers, the most common reason was "I don't need charge to use the app", and users were conscious that they could use it for free. The next most common reason was "I really want to use with charge but have no money for charge."

\subsection{Awareness of guidelines}

When asked about the experience of Gacha, it was about 36\% users who get only free Gacha, and about 55\% users who also turn paid Gacha. As experience of the Gacha, it can be said that it is more than $90 \%$.

Only $17 \%$ knew the guidelines for Gacha in 2016, the probability notice was not well recognized. $65 \%$ answered that the probability should be displayed, and there were many users who wanted the probability notice. However, when asked the question whether the action to Gacha changes depending on the disclosed information, they answered as follows. Only $27 \%$ users were "increasing opportunity to turn Gacha", "game usage time increased" was $14 \%$, "charges increased" was $13 \%$. Although the probability notation was approved, there was no positive influence on the behavior.

About recognition of guidelines, $43 \%$ in 2018 and $50 \%$ in 2019 have increased awareness. Half users still have not known it. However, even if it is not recognized as a guideline, it is becoming more common to use probability notice. For those who are conscious about the probability notice of Gacha, 40\% in 2018 answered that "it is anxious" and "temporarily" was 30\%.

On the other hand, $24 \%$ chose "I know that there is a notation but do not care." The question was changed a bit because it became normal to be displayed in 2019. As a result, "I am sure to check, or I mind about the probability information " exceeded $50 \%$, and "I do not mind the probability information" decreased to about $20 \%$. There were about $8 \%$ of users who "do not watch intentionally".

\section{Analysis of Questionnaire Results}

\subsection{Intention for charged game play}

The questionnaire results about what is important in using the game app are shown in Table 1. Other research results on social games, not limited to gacha, pointed out that the motivation for charging was that they could afford to pay themselves because of limiting the number of games and connecting with friends. However, in this research, the purpose of social games, such as ranking that makes it easy to understand the connection with others, is not the purpose of the game. Rather, the main purpose is to clear the game itself and collect characters and items, and the characteristics of a social game cannot be captured.

The result is analyzed causality to "charge" by structural equation modeling. The hypothesis model is shown in Figure 1. Table 2 shows results of analysis with the results for 2018, the results for 2019, and the results of focusing only on charge users of 2019. In 2018 results, characters are more important than connections between users, and game play that emphasizes characters affects charge. In the 2019 results, both characters and social factors were affected. However, when charging attention only to the paying users, it was found that the effect of the character was still stronger. 
Table 1: Results about intention for game play

\begin{tabular}{|c|c|c|c|c|c|c|}
\hline & 1 & 2 & 3 & 4 & 5 & 6 \\
\hline \multirow{2}{*}{$\begin{array}{l}\text { q17: I want to be ranked high in } \\
\text { games. }\end{array}$} & $15.3 \%$ & $11.1 \%$ & $8.8 \%$ & $34.7 \%$ & $14.8 \%$ & $15.3 \%$ \\
\hline & $18.3 \%$ & $15.6 \%$ & $13.4 \%$ & $29.6 \%$ & $13.4 \%$ & $9.7 \%$ \\
\hline \multirow{2}{*}{$\begin{array}{l}\text { q18: I'm concerned about the rank- } \\
\text { ing. }\end{array}$} & $23.8 \%$ & $16.4 \%$ & $15.9 \%$ & $18.7 \%$ & $11.7 \%$ & $13.6 \%$ \\
\hline & $28.8 \%$ & $17.4 \%$ & $10.9 \%$ & $25.5 \%$ & $10.3 \%$ & $7.1 \%$ \\
\hline \multirow{2}{*}{$\begin{array}{l}\text { q19: I want to win to other users in } \\
\text { games. }\end{array}$} & $14.8 \%$ & $5.1 \%$ & $7.4 \%$ & $30.6 \%$ & $21.3 \%$ & $20.8 \%$ \\
\hline & $14.0 \%$ & $12.4 \%$ & $10.8 \%$ & $23.7 \%$ & $19.9 \%$ & $19.4 \%$ \\
\hline \multirow{2}{*}{$\begin{array}{l}\text { q20: I want to show off to others in } \\
\text { games. }\end{array}$} & $18.2 \%$ & $12.1 \%$ & $15.9 \%$ & $22.4 \%$ & $11.7 \%$ & $19.6 \%$ \\
\hline & $15.8 \%$ & $19.6 \%$ & $16.3 \%$ & $21.7 \%$ & $14.1 \%$ & $12.5 \%$ \\
\hline \multirow{2}{*}{$\begin{array}{l}\text { q21: I want to clear the dungeons } \\
\text { and stages in games. }\end{array}$} & $6.9 \%$ & $4.2 \%$ & $8.8 \%$ & $22.2 \%$ & $27.8 \%$ & $30.1 \%$ \\
\hline & $7.0 \%$ & $2.7 \%$ & $4.8 \%$ & $23.7 \%$ & $28.0 \%$ & $33.9 \%$ \\
\hline \multirow{2}{*}{$\begin{array}{l}\text { q22: I want to play if there are events } \\
\text { in games. }\end{array}$} & $6.0 \%$ & $5.1 \%$ & $3.3 \%$ & $23.3 \%$ & $30.7 \%$ & $31.6 \%$ \\
\hline & $5.9 \%$ & $1.6 \%$ & $4.3 \%$ & $24.2 \%$ & $32.8 \%$ & $31.2 \%$ \\
\hline \multirow{2}{*}{ q23: Character design is important. } & $6.0 \%$ & $2.8 \%$ & $1.9 \%$ & $12.0 \%$ & $20.8 \%$ & $56.5 \%$ \\
\hline & $5.4 \%$ & $1.1 \%$ & $2.2 \%$ & $10.2 \%$ & $20.4 \%$ & $60.8 \%$ \\
\hline \multirow{2}{*}{$\begin{array}{l}\text { q24: Character voice (or sound ef- } \\
\text { fects) is important. }\end{array}$} & $11.1 \%$ & $2.8 \%$ & $4.6 \%$ & $17.1 \%$ & $19.9 \%$ & $44.4 \%$ \\
\hline & $8.1 \%$ & $2.7 \%$ & $5.4 \%$ & $14.0 \%$ & $19.9 \%$ & $50.0 \%$ \\
\hline \multirow{2}{*}{$\begin{array}{l}\text { q25: I want stronger (superior) } \\
\text { characters and items. }\end{array}$} & $6.9 \%$ & $3.7 \%$ & $5.1 \%$ & $23.6 \%$ & $22.7 \%$ & $38.0 \%$ \\
\hline & $7.6 \%$ & $1.1 \%$ & $4.3 \%$ & $22.7 \%$ & $29.7 \%$ & $34.6 \%$ \\
\hline \multirow{2}{*}{$\begin{array}{l}\text { q26: I want to collect the characters } \\
\text { and items. }\end{array}$} & $6.9 \%$ & $7.4 \%$ & $9.7 \%$ & $25.0 \%$ & $19.4 \%$ & $31.5 \%$ \\
\hline & $6.5 \%$ & $5.4 \%$ & $7.6 \%$ & $28.6 \%$ & $22.7 \%$ & $29.2 \%$ \\
\hline
\end{tabular}

upper:2018 lower:2019

1. disagree $\rightarrow 6$. agree

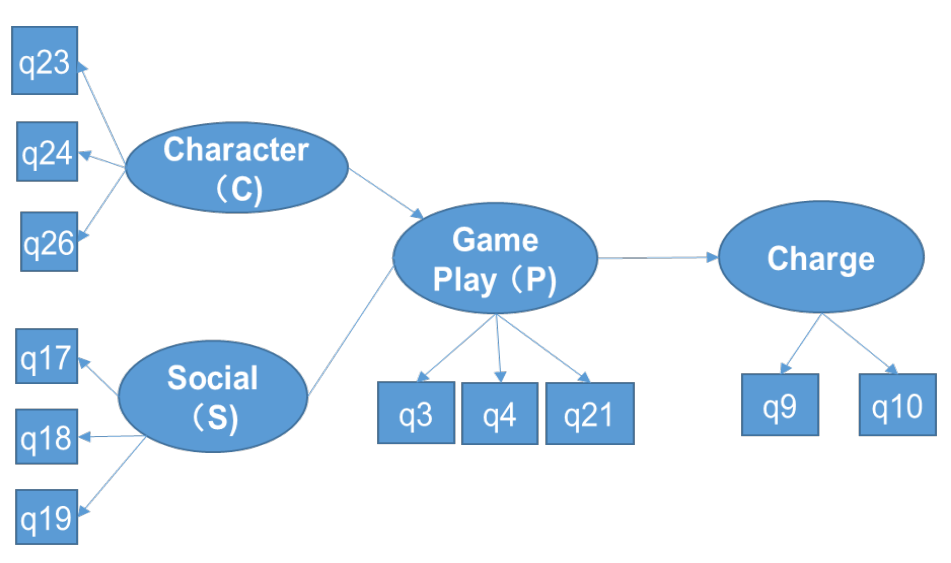

Figure 1: Relations of motivation to charge

Table 2: Results of SEM for charge motivation

\begin{tabular}{|l|l|l|r|}
\cline { 2 - 4 } \multicolumn{1}{l|}{} & 2018 & 2019 & 2019(charge users) \\
\hline $\mathrm{C} \rightarrow \mathrm{P}$ & 0.565 & 0.453 & 0.540 \\
\hline $\mathrm{S} \rightarrow \mathrm{P}$ & 0.280 & 0.403 & 0.242 \\
\hline $\mathrm{P} \rightarrow$ Charge & 0.626 & 0.489 & 0.579 \\
\hline
\end{tabular}




\subsection{Motivation for Gacha}

Table 3 shows the results of questionnaire about the reason for turning Gacha. The purpose of collecting characters and items is strong, and game clear and ranking is low. Events such as time-limited characters have become the opportunity to get Gacha. There are many users who think that even rare characters will hit someday. The reason for this is that according to the direct interview, there is actually an experience in the past or someone close to the users.

Table 4 shows the results of questions for the probability notice (estimated price notice) of Gacha. Although there are many positive opinions on the information disclose, it may not affect the motives and the number of times to turn Gacha. Even if the low probability is shown, it seems that the users who have the intentions to Gacha turn it unchanged. As the question q40, they may not trust the probability itself. However, this is not a doubt in the negative recognition, but rather, they may think "it is actually a bit more probable". Therefore, in the 2019 questionnaire, adding the question "It is easier to hit than the probability announced", the positive opinion was only $13 \%$. On the other hand, asking the question with a specific example, "If you can turn Gacha in 10 consecutive times, what do you think is the rarest character and what appearance probability characters and items will be available?" The most common responses were "1\% or less" (32\%), "0.1\% or less" (23\%), and 3rd place "0.01\% or less" (18\%). Considering the original probability, "10\% or less" is $14 \%$ less than the above.

Table 3: Results about Motivation for gacha

\begin{tabular}{|l|r|r|r|r|r|r|}
\hline & 1 & 2 & 3 & 4 & 5 & 6 \\
\hline \multirow{2}{*}{ q27: I want new characters (items) } & $8.8 \%$ & $6.0 \%$ & $9.3 \%$ & $20.8 \%$ & $19.9 \%$ & $35.2 \%$ \\
\cline { 2 - 7 } & $6.5 \%$ & $3.2 \%$ & $9.7 \%$ & $27.4 \%$ & $23.1 \%$ & $30.1 \%$ \\
\hline \multirow{2}{*}{ q28: To get the target characters (items) } & $7.0 \%$ & $4.7 \%$ & $5.1 \%$ & $16.3 \%$ & $17.2 \%$ & $49.8 \%$ \\
\cline { 2 - 7 } & $5.4 \%$ & $1.1 \%$ & $2.7 \%$ & $19.9 \%$ & $23.7 \%$ & $47.3 \%$ \\
\hline \multirow{2}{*}{ q29: To clear games } & $17.8 \%$ & $15.4 \%$ & $15.9 \%$ & $20.6 \%$ & $16.4 \%$ & $14.0 \%$ \\
\cline { 2 - 7 } & $17.9 \%$ & $15.8 \%$ & $21.2 \%$ & $19.6 \%$ & $11.4 \%$ & $14.1 \%$ \\
\hline \multirow{2}{*}{ q30: To advance the game } & $21.7 \%$ & $14.6 \%$ & $14.2 \%$ & $19.8 \%$ & $14.6 \%$ & $15.1 \%$ \\
\cline { 2 - 7 } & $21.5 \%$ & $14.0 \%$ & $14.0 \%$ & $21.5 \%$ & $14.5 \%$ & $14.5 \%$ \\
\hline \multirow{2}{*}{ q31: To rank up } & $33.0 \%$ & $16.0 \%$ & $16.5 \%$ & $14.2 \%$ & $9.9 \%$ & $10.4 \%$ \\
\cline { 2 - 7 } & $32.6 \%$ & $21.2 \%$ & $17.4 \%$ & $14.1 \%$ & $7.1 \%$ & $7.6 \%$ \\
\hline \multirow{2}{*}{ q32: If there is a probability UP event } & $13.6 \%$ & $5.6 \%$ & $5.6 \%$ & $21.6 \%$ & $25.4 \%$ & $28.2 \%$ \\
\cline { 2 - 7 } & $9.1 \%$ & $3.2 \%$ & $4.3 \%$ & $25.8 \%$ & $24.2 \%$ & $33.3 \%$ \\
\hline \multirow{2}{*}{$\begin{array}{l}\text { q33: If limited-time characters (items) } \\
\text { are provide }\end{array}$} & $9.0 \%$ & $4.2 \%$ & $4.2 \%$ & $21.7 \%$ & $23.1 \%$ & $37.7 \%$ \\
\hline \multirow{2}{*}{$\begin{array}{l}\text { q34: If there are sale events such as } \\
\text { price reduction }\end{array}$} & $7.0 \%$ & $2.7 \%$ & $5.9 \%$ & $25.3 \%$ & $26.9 \%$ & $32.3 \%$ \\
\hline $\begin{array}{l}\text { q35: I think some rare characters } \\
\text { items) will hit someday }\end{array}$ & $19.6 \%$ & $7.5 \%$ & $9.8 \%$ & $22.9 \%$ & $16.4 \%$ & $23.8 \%$ \\
\cline { 2 - 7 } & $15.1 \%$ & $8.6 \%$ & $5.4 \%$ & $27.6 \%$ & $17.8 \%$ & $25.4 \%$ \\
\cline { 2 - 6 } & $5.9 \%$ & $3.8 \%$ & $9.2 \%$ & $25.9 \%$ & $27.0 \%$ & $28.1 \%$ \\
\hline \multirow{2}{*}{ upper:2018 lower:2019 } & & & & 1. & disagree $\rightarrow 6$. agree
\end{tabular}


Table 4: Attitude to gacha guideline

\begin{tabular}{|c|c|c|c|c|c|c|}
\hline & 1 & 2 & 3 & 4 & 5 & 6 \\
\hline \multirow{2}{*}{$\begin{array}{l}\text { q36: Probability (estimated price) } \\
\text { should be noticed }\end{array}$} & $16.4 \%$ & $7.9 \%$ & $7.5 \%$ & $25.2 \%$ & $15.0 \%$ & $28.0 \%$ \\
\hline & & $5.4 \%$ & $10.3 \%$ & $20.1 \%$ & $20.1 \%$ & $34.2 \%$ \\
\hline \multirow{2}{*}{$\begin{array}{l}\text { q37: I feel relieved to be noticed even } \\
\text { with low } \\
\quad \text { probability. }\end{array}$} & $17.5 \%$ & $9.0 \%$ & $8.5 \%$ & $22.6 \%$ & $18.9 \%$ & $23.6 \%$ \\
\hline & $13.0 \%$ & $6.0 \%$ & $9.2 \%$ & $25.5 \%$ & $15.8 \%$ & $30.4 \%$ \\
\hline \multirow{2}{*}{$\begin{array}{l}\text { q38: It is easier to turn Gacha if the } \\
\text { probability is known }\end{array}$} & $21.7 \%$ & $11.8 \%$ & $11.3 \%$ & $21.7 \%$ & $13.2 \%$ & $20.3 \%$ \\
\hline & $18.1 \%$ & $11.5 \%$ & $13.2 \%$ & 24.2 & $14.8 \%$ & $18.1 \%$ \\
\hline \multirow{2}{*}{$\begin{array}{l}\text { q39: Even if a very low probability is } \\
\text { presented, it is } \\
\text { possible to turn Gacha }\end{array}$} & $21.0 \%$ & $11.7 \%$ & $8.4 \%$ & $22.0 \%$ & $11.7 \%$ & $25.2 \%$ \\
\hline & $16.3 \%$ & $8.2 \%$ & $12.5 \%$ & $27.7 \%$ & $15.8 \%$ & $19.6 \%$ \\
\hline \multirow{2}{*}{$\begin{array}{l}\text { q40: I think the probability (estimated } \\
\text { price) noticed in } \\
\text { Gacha is correct }\end{array}$} & $27.6 \%$ & $13.1 \%$ & $19.6 \%$ & $19.2 \%$ & $11.2 \%$ & $9.3 \%$ \\
\hline & $25.9 \%$ & $15.7 \%$ & $22.7 \%$ & $21.6 \%$ & $9.7 \%$ & $4.3 \%$ \\
\hline \multirow{2}{*}{$\begin{array}{l}\text { q41: I am satisfied with the probability } \\
\text { (estimated price) } \\
\text { notation of Gacha }\end{array}$} & $27.6 \%$ & $10.3 \%$ & $17.8 \%$ & $24.8 \%$ & $12.6 \%$ & $7.0 \%$ \\
\hline & $20.0 \%$ & $13.5 \%$ & $21.6 \%$ & $29.2 \%$ & $10.3 \%$ & $5.4 \%$ \\
\hline
\end{tabular}

upper:2018 lower:2019

1 . disagree $\rightarrow 6$. agree

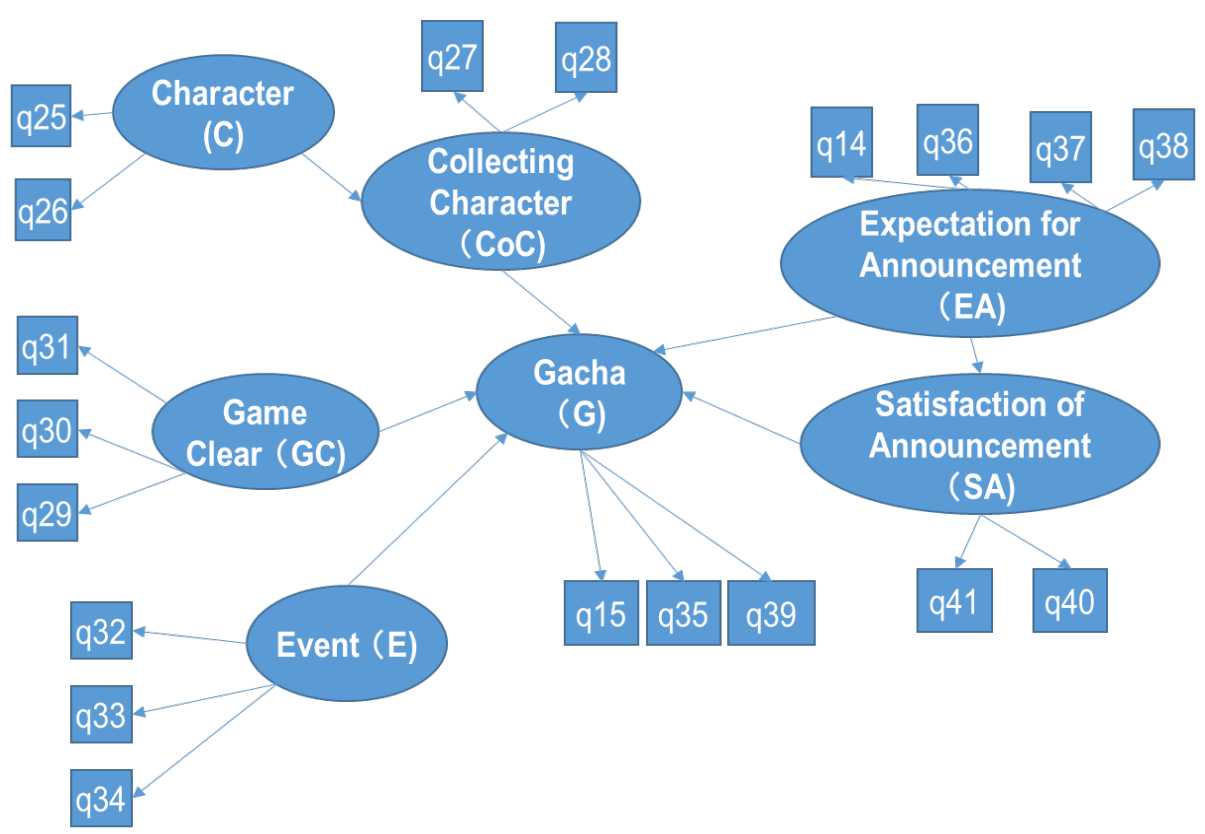

Figure 2: Hypothetical model of intention to gacha (2018)

Based on the results of 2018 , it is analyzed whether the motivation and probability notation of gacha affect the behavior of turning Gacha by causal hypothesis as shown in Figure 2 and by structural equation modeling. Table 5 shows the analysis results. The motivation to turn Gacha is most strongly influenced by the consciousness that the character likes and wants to collect. On the other hand, events have little effect on Gacha. In addition, there was also an effect of having expectations on the probability notation, and if the probability was satisfied with the notation, it led to the action of turning gacha. In particular, when limited to 
charge users, the effect on Gacha from character collection is even stronger, and the effect of probability notation is smaller. In the case of non-charge users, they want to collect characters if they like the characters, but that does not lead to the action of turning gacha. Rather, they focus on limited-time events such as increasing the probability, and try to get better items as far as they can do without charging. In addition, it is considered that the effect of the probability notation affects the behavior to Gacha compared to the charge users.

Table 5: Results of SEM for gacha intention (2018)

\begin{tabular}{|l|r|r|r|}
\hline & \multicolumn{1}{|c|}{ all } & \multicolumn{1}{c|}{ charge } & non-charge \\
\hline $\mathrm{C}->\mathrm{CoC}$ & 0.771 & 0.719 & 0.835 \\
\hline $\mathrm{CoC}->\mathrm{G}$ & 0.874 & 0.951 & 0.188 \\
\hline $\mathrm{GC}->\mathrm{G}$ & 0.12 & 0.306 & 0.229 \\
\hline $\mathrm{E}->\mathrm{G}$ & -0.109 & -0.305 & 0.485 \\
\hline $\mathrm{EA}->\mathrm{G}$ & 0.061 & 0.071 & 0.213 \\
\hline $\mathrm{EA}->\mathrm{SA}$ & 0.347 & 0.279 & 0.464 \\
\hline $\mathrm{SA}->\mathrm{G}$ & 0.238 & 0.131 & 0.486 \\
\hline
\end{tabular}

Based on the analysis of 2018 results, in analysis of 2019, factors related characters are further focused on. Event is limited to events related to characters, and further divide into expecting and satisfying actions to turn Gacha. The changed hypothesis model is shown in Figure 3. Table 6 shows the results of analysis by structural equation modeling. The analysis was divided into charged and non-charged users, and charged users were divided into high and low charges based on a monthly charge of 3,000 yen.

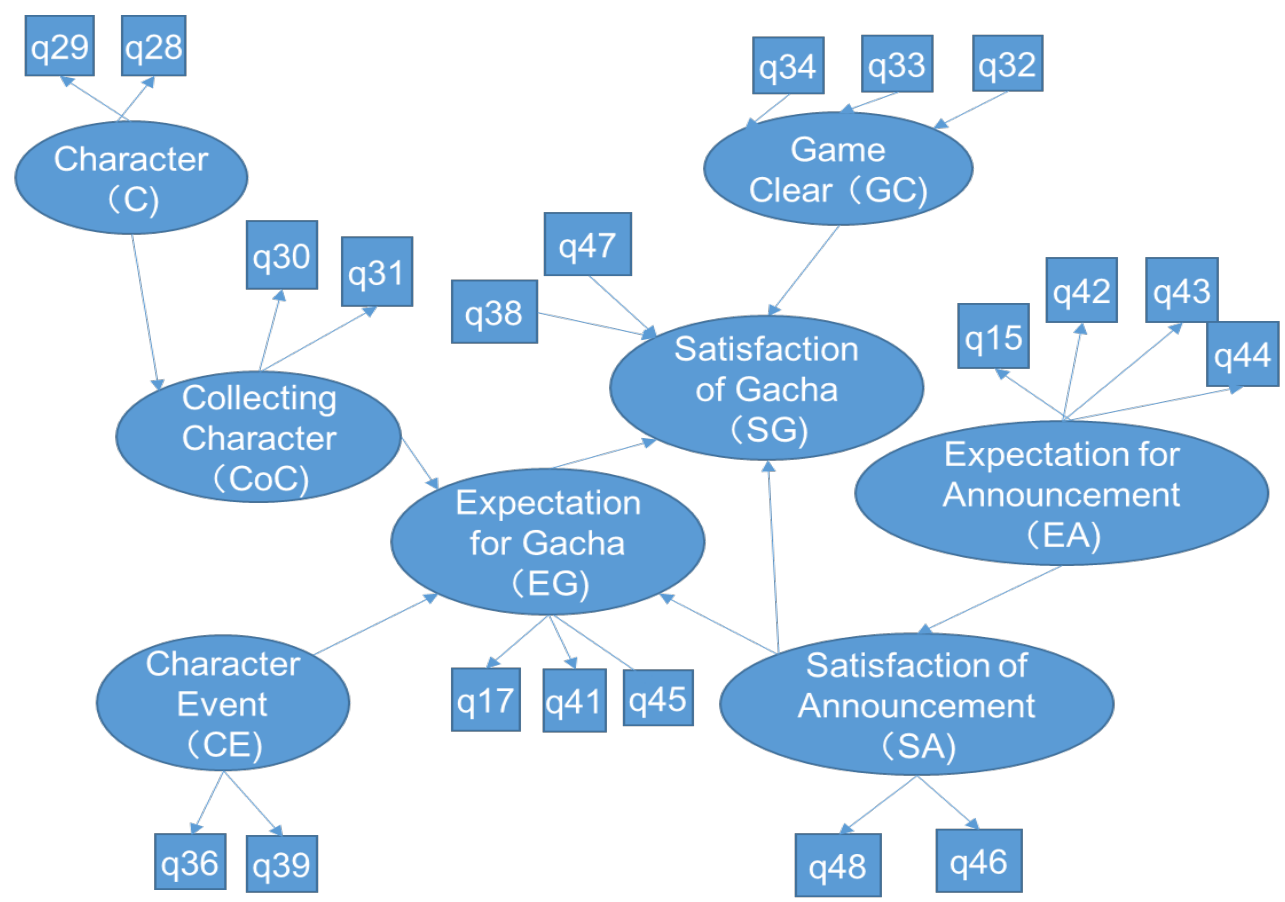

Figure 3: Hypothetical model of intention to gacha (2019) 
Table 6: Results of SEM for gacha intention (2019)

\begin{tabular}{|l|r|r|r|r|r|}
\hline & \multicolumn{1}{|c|}{ all } & non-charge & \multicolumn{1}{c|}{ charge } & \multicolumn{1}{c|}{$\begin{array}{c}\text { charge } \\
\text { (over 3,000) }\end{array}$} & $\begin{array}{c}\text { charge } \\
\text { (under3,000) }\end{array}$ \\
\hline C -> CoC & 0.965 & 0.955 & 0.934 & 0.914 & 1.202 \\
\hline CoC -> EG & 0.481 & 0.114 & 0.500 & 0.497 & 0.253 \\
\hline CE -> EG & 0.570 & 0.656 & 0.455 & 0.109 & 0.786 \\
\hline EA -> SA & 0.462 & 0.596 & 0.468 & 0.433 & 0.236 \\
\hline SA -> EG & 0.367 & 0.746 & 0.307 & 0.260 & 0.487 \\
\hline EG -> SG & 0.434 & 0.946 & 0.320 & 0.420 & -0.171 \\
\hline GC -> SG & 0.030 & 0.113 & 0.017 & 0.072 & -0.097 \\
\hline SA -> SG & 0.740 & -0.408 & 0.781 & 0.597 & 1.058 \\
\hline
\end{tabular}

As a whole result, by limiting the event factors to character events, the effect of expecting gacha by events has been observed compared to the 2018 model. As for the probability notation, if users were satisfied with the probability notation, they had a positive effect that they were satisfied with Gacha. Gacha satisfaction is roughly divided into the factors related to the character on the left side of the model diagram and the factors related to the probability notation on the right side. Considering the overall effect, they are 0.45 and 0.42 , respectively, which are almost the same.

According to the results of non-charge users, they like the characters and want to collect characters, but that does not significantly affect their expectations for Gacha. If there is a character event, they expect Gacha. If they are satisfied with the probability notation, the direct effect to satisfaction with Gacha has a negative value, but it has a large effect on the expectation of Gacha and is not a negative factor considering the indirect effect. However, as in the analysis of all users, considering the overall effect, the effect is as large as 0.72 from the character, but as small as 0.18 from the probability notation. For non-charge users, the probability up event etc. is important, and the notation of low probability at normal times may be a factor that prevents turning back gacha.

Highly charged users with monthly fees of 3,000 yen or more are less affected by character events than other users. As for the probability notation, the same effect as the effect from the character is seen, and it is considered that the notation is minded while constantly expecting Gacha for character collection. On the other hand, low charge users who charge less than 3,000 yen are as event-oriented as non-charge users, and seem to be most interested in probability information in order to obtain the desired item efficiently with a small charge.

\section{Conclusions}

The questionnaire survey analyzed users' attitude about social games, especially Gacha with charge. The motivation and charge tendency of Gacha were examined considering the effect of gacha guidelines. Both the motivation to play the game and the motivation to turn gacha are divided into users who make a point of social factors in games and users who focus on character collection. The character-oriented type became the majority in this survey. Although the awareness of the guidelines has increased, it cannot be said that the notation itself has influenced the behavior of turning Gacha. The users' consciousness and 
attitude greatly differ between charge users and non-charge users. The causal relationship between the motive of the gacha and the probabilistic notation was analyzed separately for charging and non-charging users. The non-charge users emphasized events and were not much affected by the probability information itself. When there is no event, there is no need to be aware of the normal probability notation, because it does not try to turn Gacha. In addition, the number of times the gacha is turned may be limited, and if it is known that the probability is very low, it is highly likely that the action of turning Gacha will not be performed. On the other hand, highly charge users are more likely to agree with the probability notation, either because they consider the contents of the notation (probability or estimated price) to be reasonable, or because they are guaranteed to obtain items by paying a certain amount of money. Therefore probability information can affect satisfaction. Lowly charge users are closer to non-charge users, but are more conscious of not only using events but also using the probability notation of Gacha more effectively so as not to waste charge.

After the guidelines were formulated, probability notation has become common, but not only the notation but also various ideas have been seen in the gacha system itself. For example, there has been a device such as a post-payment gacha that charges when an item that comes out by turning a gacha is liked. Since various methods are provided in this way, it is thought that the motivation and expectation for gacha will differ depending on the game to be played, and further investigation is required.

\section{References}

[1] Ministry of Internal Affairs and Communications Japan, Information and Communications in Japan WHITE PAPER 2018.

[2] Chris Anderson, Free : The Future of a Radical Price, Hyperion, 2009.

[3] Noriko Arai, "The Anal ysis of the Social Psychological Factors That Influence the Enthusiasm of Social Game", Sophia Economic Review, Vol.58, No.1/2, 2013, pp.277-287 (in Japanese).

[4] Kumiko Nobusawa, "Legal Problems of Online Games", Journal of Aoyama Gakuin Women's Junior College, Vol.70, 2016, pp.69-81 (in Japanese).

[5] Koeder, Tanaka, and Mitomo, "Exploring the game-of-chance elements in F2P mobile games - Ins ights of player's emotions from qualitative analysis -“, DHU JOURNAL Vol. 5, 2018, pp.16-28.

[6] Japan Online Game Association: Disclosure and operational guidelines in item sales that make use of randomly dropped items, 2016.

[7] Computer Entertainment Supplier's Association: Operational guidelines for randomly item provision system in network games, 2016.

[8] Mark D. Griffiths, "Adolescent gambling and gambling-type games on social networking sites Issues, concerns, and recommendations", Aloma: Revista de Psicologia, Ciències de l'Educació i de l'Esport, Vol.33, 2015, pp.31-37.

[9] Han and Windsor, "An investigation of the smartphone user's in-game purchase intention", International Journal of Mobile Communications, Vol.11, Issue 6, 2013, pp.617635. 
[10] Hsiao and Chen, "What drives in-app purchase intention for mobile games? An examination of perceived values and loyalty", Electronic Commerce Research and Applications. Vol.16, 2016, pp.18-29.

[11] Mamari, Alha, Jarvela, Kivikangas, Koivisto, and Paavilainen, “Why do players buy in-game content? An empirical study on concrete purchase motivations", Computers in Human Behavior, Vol.68, 2017, pp.538-546.

[12] Balakrishnana and Griffithsb, "Loyalty towards online games, gaming addiction, and purchase intention towards online mobile in-game features", Computers in Human Behavior, Vol. 87, 2018, pp238-246.

[13] Ayako Hiramatsu, "A Survey of Social Game Users about "Gacha" Probability Display”, The papers of Technical Meeting on Information Systems, IEE Japan, IS-17-008, 2017, pp.41-44 (in Japanese).

[14] Ayako Hiramatsu, “A Research of Social Game Users' Attitude to "Gacha" Probability Announcement", Proc. of 8th International Congress on Advanced Applied Informatics (IIAI AAI 2019), 2019, pp.115-120. 